\title{
Combined Effect of Variable Permeability and Variable Magnetic field on MHD Flow past an inclined plate with exponential Temperature and Mass Diffusion with Chemical reaction through Porous media
}

\author{
N. Pandya ${ }^{1}$, M. S. Quraishi ${ }^{2 *}$ \\ ${ }^{1}$ Department of Mathematics \& Astronomy, University of Lucknow, 226007, Lucknow, India, \\ ${ }^{2}$ Department of Mathematics \& Astronomy, University of Lucknow, 226007, Lucknow, India \\ *Corresponding Author: sulemanformaths86@gmail.com, Mobile Number: 9389204170.
}

Available online at: www.isroset.org

Received:31/Aug/2018, Accepted:14/Oct/2018, Online: 31/Oct/2018

\begin{abstract}
In this research article we have investigated that combined effects of variable permeability and variable magnetic field in the presence of chemical reaction on unsteady MHD (Magnetohydrodynamics) flow of a viscous incompressible fluid past an inclined plate through porous medium with exponential temperature and concentration. The governing equations of non-dimensional forms of flow field have been solved numerically using Crank-Nicolson implicit finite difference method. The results are obtained for velocity, temperature and concentration. The effects of various parameters by taking different values of them are resulted and discussed on flow variables like velocity, temperature and concentration are presented through graphs and tables.
\end{abstract}

Keywords: Variable permeability and variable magnetic field, Chemical reaction and Crank-Nicolson finite difference method.

\section{INTRODUCTION}

The MHD flow has been discussing since last decades in various field of science and engineering. The study over MHD flow over a flat porous plate is interesting and classical but vital problem in fluid dynamics which has applications in many engineering problems such as MHD generators, nuclear reactors, oil exploration, solar plasma studies, geothermal energy extractions, in the field of aerodynamics in the boundary layer control, flow occurs in solid mechanics, flow of water containing oil in packed rocks with various porosity, oil recovering through ocean wells and ground water hydrology purification of the crude oil in industries. In the fluid dynamics theory the mass transfer is very common principle in theory of burning a pool of oil, drying and leaching by spray and mass transport process of animal and plant life. Effect of Magnetic field on free convection heat transfer, by E. M. Sparrow, R. D. Cess [1], Dufour and Soret effect on MHD free convective Heat and Mass transfer flow past a vertical flat plate embedded in a porous medium, by M. S. Alam, M. M. Rahman [2], it is investigated Diffusion thermo and thermal diffusion effects in transient and steady natural convection from vertical surface by Z. Dursunkaya, W.M. Worek [3], Influence of a magnetic field on heat and mass transfer by natural convection from vertical surface in porous media considering Soret and Dufour effects by A. Postelnicu [4], Further worked Radiation and free convection flow past a moving plate by A. Raptis, C. Perdikis [5], Radiation and mass transfer effects on MHD free convection flow past an exponentially accelerated vertical plate with variable temperature by V. Rajesh, V. K. Verma[6], it analyzed Chemical reaction effect on an unsteady MHD free convective flow past and infinite vertical porous plate with constant suction and heat source by S. Shivaiah and J. A. Rao [7] , it worked, Laminar convection in binary mixed of Hydro magnetic flow with Radiative Heat Transfer by M.A. Alabraba, A.R. Bestman, A. Ogulu [8], then investigated Dufour and Soret effect on steady MHD flow in presence of Heat generation and magnetic field past an inclined stretching sheet by M.D. Enamul Karim, M.D. Abdus Samad, M.D. Maruf Hasan [9], We have analyzed Effect of Soret and Rotation on MHD unsteady flow past an inclined infinite porous plate embedded in porous medium with heat generation/ absorption and mass transfer [10],Further we have investigated, Effect of Chemical Reaction and Rotation on MHD unsteady flow past an inclined oscillating infinite porous plate embedded in porous medium for heat 
generation/ absorption with mass transfer and variable temperature [11].

The objective of this research article is to analyze the combined effects of variable permeability and variable magnetic field in the presence of Chemical reaction on unsteady MHD flow of a viscous incompressible fluid past an inclined plate through porous medium with exponentially increasing temperature and exponentially decreasing concentration. The governing equation of non-dimensional form of flow fields are solved numerically using CrankNicolson implicit finite difference method. The effect of different values of physical parameters on velocity, temperature and concentration are discussed through graphically and by the table.

\section{MATHEMATICAL FORMULATION OF THE PROBLEM}

Consider an unsteady MHD flow of a viscous incompressible electrically conducting fluid past an infinite inclined plate with variable temperature, concentration, Chemical reaction with variable permeability and magnetic field has been studied. The plate is embedded in porous medium and inclined at angle $\lambda$ to vertical. $\mathrm{x}^{\prime}$-axis is taken along the plate and $\mathrm{y}$-axis is normal to it. A variable magnetic field $\mathrm{B}_{0}$ is taken in $\mathrm{z}$-axis and plate is electrically non-conducting. Consider $\mathrm{y}$-axis normal to $\mathrm{x}-\mathrm{z}$ plane. Initially the plate and fluid are at the same temperature and concentration $\mathrm{T}_{\infty}^{\prime}$ and $\mathrm{C}_{\infty}^{\prime}$ respectively. At the time $\mathrm{t}^{\prime}>0$ plate is given in motion along $\mathrm{x}$ ' direction with constant velocity $u_{0}$. A transverse variable magnetic field $B_{0}$ is considered normal to the direction of flow. Magnetic Reynold number and transversely applied magnetic field are very small therefore induced magnetic field is negligible [12]. Due to infinite length in $x^{\prime}$-direction the flow variables are functions of $y^{\prime}$ and t' only. Under the above

Assumptions, the governing boundary layer equations with Boussinesq's approximation are

\section{A. Momentum equations}

$\frac{\partial u^{\prime}}{\partial t^{\prime}}=v \frac{\partial^{2} u^{\prime}}{\partial y^{\prime 2}}+g \beta \operatorname{Cos} \lambda\left(T^{\prime}-T_{\infty}^{\prime}\right)+g \beta^{*} \operatorname{Cos} \lambda\left(C^{\prime}-C_{\infty}^{\prime}\right)-\frac{\sigma B_{0}{ }^{2} u^{\prime}}{\rho}-\frac{v u^{\prime}}{K^{\prime}}$

\section{Energy equation}

$$
\rho C_{p} \frac{\partial \mathrm{T}^{\prime}}{\partial \mathrm{t}^{\prime}}=\mathrm{k} \frac{\partial^{2} \mathrm{~T}^{\prime}}{\partial \mathrm{y}^{\prime 2}}
$$

\section{B. Equation of mass transfer}

$$
\frac{\partial \mathrm{C}^{\prime}}{\partial \mathrm{t}^{\prime}}=\mathrm{D} \frac{\partial^{2} \mathrm{C}^{\prime}}{\partial \mathrm{y}^{\prime 2}}-\mathrm{k}_{\mathrm{r}}\left(\mathrm{C}^{\prime}-\mathrm{C}_{\infty}^{\prime}\right)
$$

Here molecular diffusivity is $\mathrm{D}$, coefficient of volume expansion for mass transfer is $\boldsymbol{\beta}^{*}$, volumetric coefficient of thermal expansion is $\boldsymbol{\beta}$, variable magnetic induction is $\mathrm{B}_{0}$ which depends on exponentially decreasing time that is Magnetic parameter $M\left(\mathrm{t}^{\prime}\right)=\operatorname{Exp}\left(-\mathrm{t}^{\prime}\right)$, which decreases from 4 to approx zero, permeability of porous medium is $\mathrm{K}^{\prime}$ which depends on $y$ that is $\mathrm{K}^{\prime}(\mathrm{y})$ which inversely varies with the distance $y$ from the plate between 1 to 0 ,velocity component along $\mathrm{x}^{\prime}$-axis, $\mathrm{y}^{\prime}$-axis and $\mathrm{z}^{\prime}$-axis are $\mathrm{u}^{\prime}, \mathrm{v}^{\prime}$ and $\mathrm{w}^{\prime}$ respectively, electrical conductivity is $\sigma$, gravitational acceleration is $\mathrm{g}$, fluid density is $\rho$, thermal conductivity of fluid is $\mathrm{k}$, chemical reaction parameter is $\mathrm{k}_{\mathrm{r}}$, specific heat of constant pressure is $C_{p}$, dimensional temperature is $T^{\prime}$, temperature of free stream is $\mathrm{T}_{\infty}{ }^{\prime}$, dimensional concentration is $\mathrm{C}^{\prime}$, concentration of free stream is $\mathrm{C}_{\infty}{ }^{\prime}$, kinematic viscosity is $v$ and mean fluid temperature is $T_{m}$.

Boundary and initial conditions are given as:

$$
\left.\begin{array}{lll}
\mathrm{t}^{\prime} \leq 0 ; & \mathrm{u}^{\prime}=0, \quad \mathrm{~T}^{\prime}=\mathrm{T}_{\infty}{ }^{\prime}, \quad \mathrm{C}^{\prime}=\mathrm{C}_{\infty}{ }^{\prime} & \forall \mathrm{y}^{\prime} \\
\mathrm{t}^{\prime}>0 ; & \mathrm{u}^{\prime}=\mathrm{u}_{0}, \quad \mathrm{~T}^{\prime}=\mathrm{T}^{\prime}+\left(\mathrm{T}_{\mathrm{w}}{ }^{\prime}-\mathrm{T}_{\infty}{ }^{\prime}\right) \mathrm{e}^{A \mathrm{t}^{\prime}}, & \\
\mathrm{C}^{\prime}=\mathrm{C}^{\prime}+\left(\mathrm{C}_{\mathrm{w}}{ }^{\prime}-\mathrm{C}_{\infty}{ }^{\prime}\right) \mathrm{e}^{-\mathrm{At}^{\prime}} \quad & \text { at } \mathrm{y}^{\prime}=0 \\
\mathrm{u}^{\prime} \rightarrow 0, & \mathrm{~T}^{\prime} \rightarrow \mathrm{T}_{\infty}^{\prime}, \quad \mathrm{C}^{\prime} \rightarrow \mathrm{C}_{\infty}{ }^{\prime} \quad \text { when } \mathrm{y}^{\prime} \rightarrow \infty
\end{array}\right\}
$$

Temperature and concentration of plate are $\mathrm{T}_{\mathrm{w}}{ }^{\prime}$ and $\mathrm{C}_{\mathrm{w}}{ }^{\prime}$ respectively.

In order to produce non-dimensional partial differential equations, introducing following dimensional less quantities:

$$
\begin{aligned}
& \mathrm{t}=\frac{\mathrm{t}^{\prime} \mathrm{u}_{0}{ }^{2}}{\mathrm{v}}, \mathrm{y}=\frac{\mathrm{y}^{\prime} \mathrm{u}_{0}}{\mathrm{v}}, \theta=\frac{\mathrm{T}^{\prime}-\mathrm{T}_{\infty}^{\prime}}{\mathrm{T}_{\mathrm{w}}^{\prime}-\mathrm{T}_{\infty}^{\prime}}, \mathrm{u}=\frac{\mathrm{u}^{\prime}}{\mathrm{u}_{0}}, \\
& \mathrm{C}=\frac{\mathrm{C}^{\prime}-\mathrm{C}_{\infty}^{\prime}}{\mathrm{C}_{\mathrm{w}}^{\prime}-\mathrm{C}_{\infty}^{\prime}}, \mathrm{K}(\mathrm{y})=\frac{\mathrm{u}_{0} \mathrm{~K}^{\prime}(\mathrm{y})}{\mathrm{v}^{2}}, \mathrm{~K}_{\mathrm{r}}=\frac{\mathrm{k}_{\mathrm{r}}}{\mathrm{u}_{0}} \\
& M(t)=\frac{\sigma B_{0}^{2}(t)}{\rho u_{0}}, P_{r}=\frac{v \rho C_{p}}{k}, S_{c}=\frac{v}{D}, \text {, } \\
& \left.\mathrm{G}_{\mathrm{r}}=\frac{v \mathrm{~g} \beta\left(\mathrm{T}_{\mathrm{w}}^{\prime}-\mathrm{T}_{\infty}^{\prime}\right)}{\mathrm{u}_{0}{ }^{3}}, \mathrm{G}_{\mathrm{m}}=\frac{v \mathrm{~g} \beta^{*}\left(\mathrm{C}_{\mathrm{w}}^{\prime}-\mathrm{C}_{\infty}^{\prime}\right)}{\mathrm{u}_{0}{ }^{3}}\right)
\end{aligned}
$$

In view of equation (5), we yield dimensionless form of equations (1), (2) and (3) respectively

$$
\frac{\partial \mathrm{u}}{\partial \mathrm{t}}=\frac{\partial^{2} \mathrm{u}}{\partial \mathrm{y}^{2}}+\operatorname{Cos} \lambda \mathrm{G}_{\mathrm{r}} \theta+\operatorname{Cos} \lambda \mathrm{G}_{\mathrm{m}} \mathrm{C}-\left(\mathrm{M}+\frac{1}{\mathrm{~K}}\right) \mathrm{u}
$$

$$
\frac{\partial \theta}{\partial t}=\frac{1}{P_{r}} \frac{\partial^{2} \theta}{\partial y^{2}}
$$




$$
\frac{\partial \mathrm{C}}{\partial \mathrm{t}}=\frac{1}{\mathrm{~S}_{\mathrm{c}}} \frac{\partial^{2} \mathrm{C}}{\partial \mathrm{y}^{2}}-\mathrm{K}_{\mathrm{r}} \mathrm{C}
$$

With boundary conditions (4) using (5) converted as:

$$
\begin{aligned}
& \mathrm{t} \leq 0 ; \quad \mathrm{u}=0, \quad \boldsymbol{\theta}=\mathbf{0}, \quad \mathbf{C}=\mathbf{O} \quad \forall \mathrm{y} \\
& \mathrm{t}>0 ; \quad \mathrm{u}=1, \quad \boldsymbol{\theta}=\mathrm{e}^{\mathrm{t}}, \quad \mathrm{C}=\mathrm{e}^{-\mathrm{t}} \text { at } \mathrm{y}=0 \\
& \text { (9) } \mathrm{u} \rightarrow 0, \quad \boldsymbol{\theta} \rightarrow 0, \quad C \rightarrow 0 \quad \mathrm{y} \rightarrow \infty
\end{aligned}
$$

Where $\mathrm{M}$ is exponentially decreasing with time and $\mathrm{K}$ decreases with distance increases from plate.
Now, it is beneficial to calculate physical quantities for primary need, these are coefficient of skin-friction $\mathrm{G}$ along $\mathrm{X}$ axis at the wall, Dimensionless forms of Nusselt number $\mathrm{Nu}$ and Sherwood number Sh., these physical quantities are:

$$
\left.\begin{array}{c}
\tau=\left(\frac{\partial u}{\partial y}\right)_{y=0}, N u=-\left(\frac{\partial \theta}{\partial y}\right)_{y=0}, \\
S h=-\left(\frac{\partial C}{\partial y}\right)_{y=0}
\end{array}\right\}
$$

Equations (7) to (9) are linear partial differential equations, are solved using initial boundary conditions (9), it is solved by Crank-Nicolson implicit finite difference method for numerical solution. Equations (6), (7), (8) and (9) are expressed as:

$$
\begin{aligned}
& \frac{u_{i, j+1}-u_{i, j}}{\Delta t}=\left(\frac{u_{i-1, j}-2 u_{i, j}+u_{i+1, j}+u_{i-1, j+1}-2 u_{i, j+1}+u_{i+1, j+1}}{2(\Delta y)^{2}}\right) \\
& +G_{r} \operatorname{Cos} \lambda\left(\frac{\theta_{i, j+1}+\theta_{i, j}}{2}\right)+G_{m} \operatorname{Cos} \lambda\left(\frac{C_{i, j+1}+C_{i, j}}{2}\right)-\left(M+\frac{1}{K}\right)\left(\frac{u_{i, j+1}+u_{i, j}}{2}\right) \\
& \frac{\theta_{i, j+1}-\theta_{i, j}}{\Delta t}=\frac{1}{P_{r}}\left(\frac{\theta_{i-1, j}-2 \theta_{i, j}+\theta_{i+1, j}+\theta_{i-1, j+1}-2 \theta_{i, j+1}+\theta_{i+1, j+1}}{2(\Delta y)^{2}}\right) \\
& \frac{C_{i, j+1}-C_{i, j}}{\Delta t}=\frac{1}{S_{c}}\left(\frac{C_{i-1, j}-2 C_{i, j}+C_{i+1, j}+C_{i-1, j+1}-2 C_{i, j+1}+C_{i+1, j+1}}{2(\Delta y)^{2}}\right)-K_{r}\left(\frac{C_{i, j+1}+C_{i, j}}{2}\right)
\end{aligned}
$$

Corresponding boundary and initial conditions are as

$$
\begin{aligned}
& \mathrm{u}_{\mathrm{i}, 0}=0, \quad \theta_{\mathrm{i}, 0}=0, \quad \mathrm{C}_{\mathrm{i}, 0}=0 \quad \forall \mathrm{i} \\
& \left.\mathrm{u}_{0, \mathrm{j}}=1, \quad \theta_{0, \mathrm{j}}=\mathrm{e}^{\mathrm{j}^{*} \Delta \mathrm{t}}, \quad \mathrm{C}_{0, \mathrm{j}}=\mathrm{e}^{-\mathrm{j}^{*} \Delta \mathrm{t}} \quad \forall \mathrm{j}\right\} \\
& \mathrm{u}_{\mathrm{L}, \mathrm{j}} \rightarrow 0, \quad \theta_{\mathrm{L}, \mathrm{j}} \rightarrow 0, \quad \mathrm{C}_{\mathrm{L}, \mathrm{j}} \rightarrow 0
\end{aligned}
$$

Here, index $I$ refers to $y$ and $j$ to time, $\Delta \mathrm{t}=\mathrm{t}_{\mathrm{j}+1}-\mathrm{t}_{\mathrm{j}}$ and $\Delta \mathrm{y}=\mathrm{y}_{\mathrm{i}+1}-\mathrm{y}_{\mathrm{i}}$.

For known values of $\mathrm{u}$, Theta and $\mathrm{C}$ at $\mathrm{t}$, we calculate these values for $t+\Delta t$ as follows, after substitution of $i=1,2,3 \ldots \mathrm{L}$ 1 , where $\mathrm{L}$ corresponds to $\infty$.
Now Equations (12) and (13), the system of equations is solved by Thomas Algorithm as discussed in Carnahan,

Luthor, Wilkes [13]. Then $\theta$ and $\mathrm{C}$ are known for all values of $y$ at $t+\Delta t$. Replacing values of $\theta$ and $C$ in equation (11) and solved by same with initial and boundary conditions given by Equation (14), we have solutions for $u$ till desired time t. Crank-Nicolson implicit finite difference method is second order method $\left(\mathrm{o}\left(\Delta \mathrm{t}^{2}\right)\right)$ in time and has no limitation for space and time steps, that is, the method is unconditionally stable.

Computation has been executed for $\Delta \mathrm{y}=0.1, \Delta \mathrm{t}=0.002$ and repeated till $\mathrm{y}(\max )=4$, where $\mathrm{y}(\max )$ corresponds to infinity.

\section{RESUlt AND DiscuSSION}

With reference of physical problem, numerical results for dimensionless velocity $\mathrm{u}$, temperature $\theta$ and concentration $\mathrm{C}$ are discussed with help of graphs by assigning numerical values of thermal Grashof number Gr, solute Grashof number Gm, Schmidt number Sc, Prandtl number Pr, 
Chemical reaction parameter $\mathrm{Kr}$ and inclination angle $\lambda$ with varying magnetic field and variable permeability.

Fig.1, 2, 3 and 4 depicts that the primary velocity ' $u$ ' decreases with increase in $\mathrm{K}_{\mathrm{r}}, \lambda, \mathrm{P}_{\mathrm{r}}$ and $\mathrm{S}_{\mathrm{c}}$ while increases with increasing time $\mathrm{t}$ Fig. 5.

Temperature profile $\theta$, in Fig. 6 and 8, shows decrement with increment in $\mathrm{P}_{\mathrm{r}}$ and increases with increment in time (t) respectively which confirms the boundary condition taken. Concentration profile ' $\mathrm{C}$ ' decreases with increment in time 't', $S_{c}$ and $K_{r}$ in Fig. 7, 9 and $10 \mathrm{Kr}$ respectively.

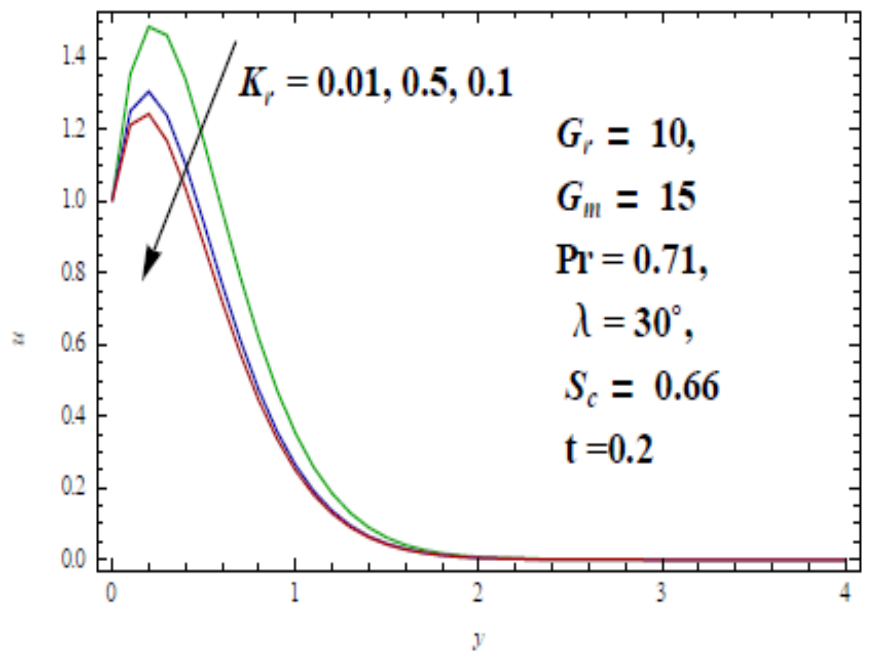

$\begin{array}{llll}\text { Figure 1. } & \mathbf{u} & \mathbf{v} / \mathbf{s} & \mathbf{K}_{\mathrm{r}}\end{array}$

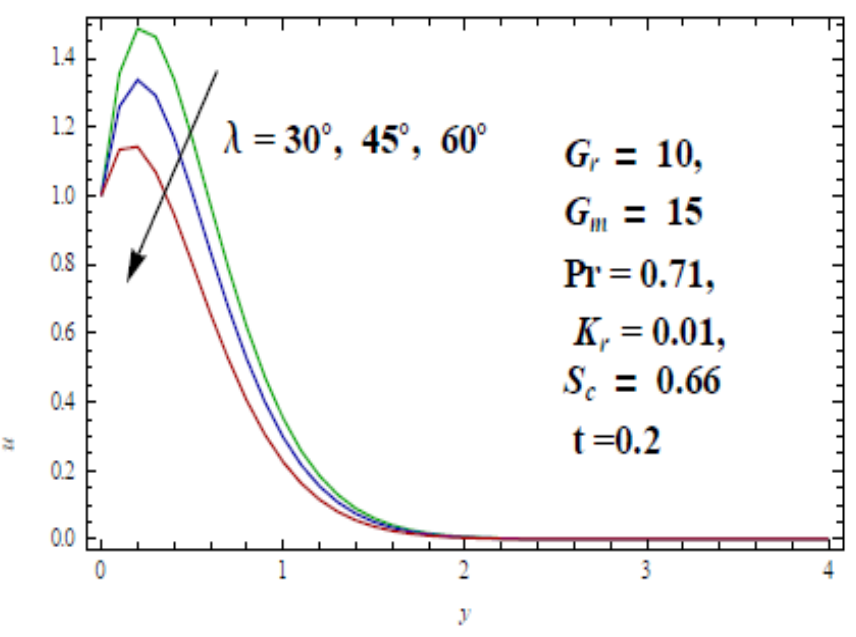

Figure 2. $\quad \mathbf{u} \quad \mathbf{v} / \mathbf{s} \quad \lambda$
Table.1 depicts that on increasing $\lambda$, the Skin friction $\mathbf{t}$ decreases while Nusselt number $\mathrm{Nu}$ and Sherwood number Sh remains same.

On increasing $\mathrm{P}_{\mathrm{r}}$ the Skin friction $\mathbf{\mathbf { c }}$ decreases and Nusselt number $\mathrm{Nu}$ increases while Sherwood number Sh remains same, on increasing time (t), the Skin friction $\mathbf{c}$ increases while Nusselt number $\mathrm{Nu}$ and Sherwood number $\mathrm{Sh}$ decrease, On increasing $\mathbf{S}_{\mathbf{c}}$ the Skin friction $\mathbf{u}$ decreases and Sherwood number $\mathrm{Sh}$ increases while Nusselt number $\mathrm{Nu}$ remains same, On increasing $K_{r}$ the Skin friction $\mathbf{u}$ decreases and Sherwood number $\mathrm{Sh}$ increases while Nusselt number $\mathrm{Nu}$ remains same.

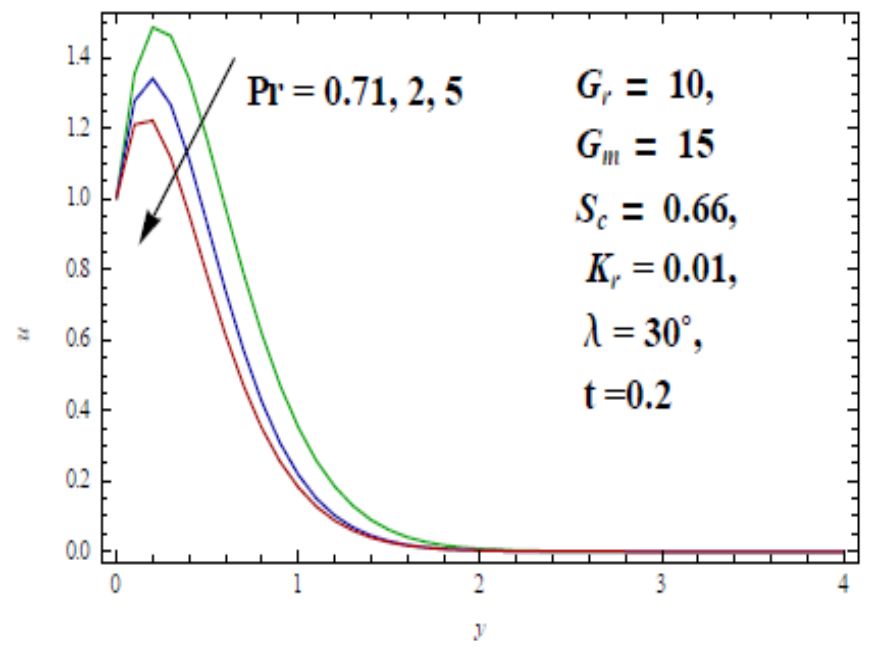

$\begin{array}{llll}\text { Figure 3. } & \mathbf{u} & \mathbf{v} / \mathbf{s} & \mathbf{P}_{\mathbf{r}}\end{array}$

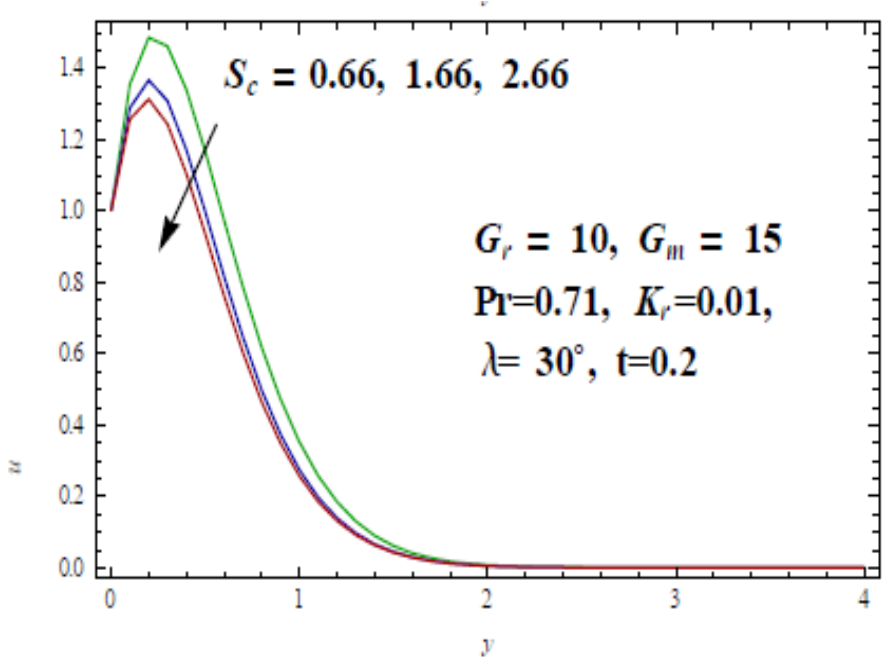

$\begin{array}{llll}\text { Figure 4. } & \mathbf{u} & \mathbf{v} / \mathbf{s} & \mathbf{S}_{\mathrm{c}}\end{array}$ 


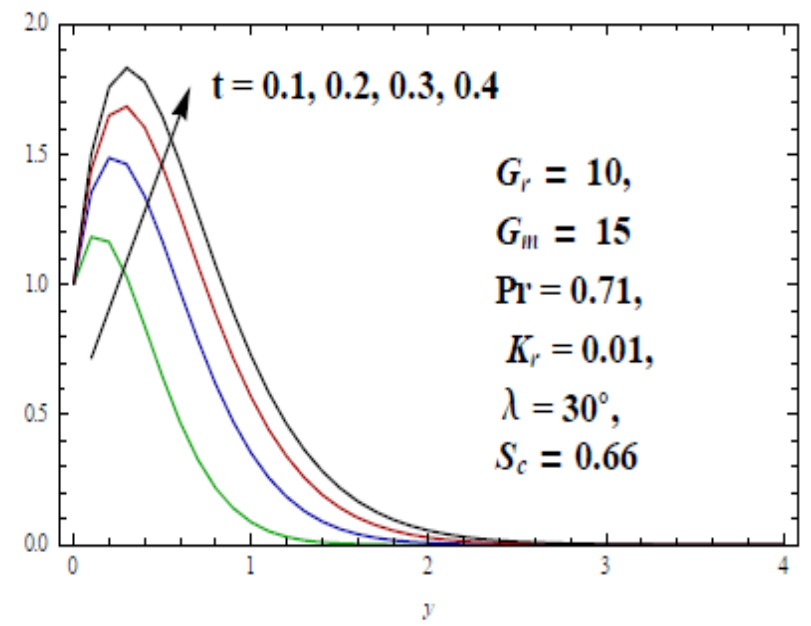

Figure 5. $\quad \mathbf{u} \quad \mathbf{v} / \mathbf{s} \quad \mathbf{t}$

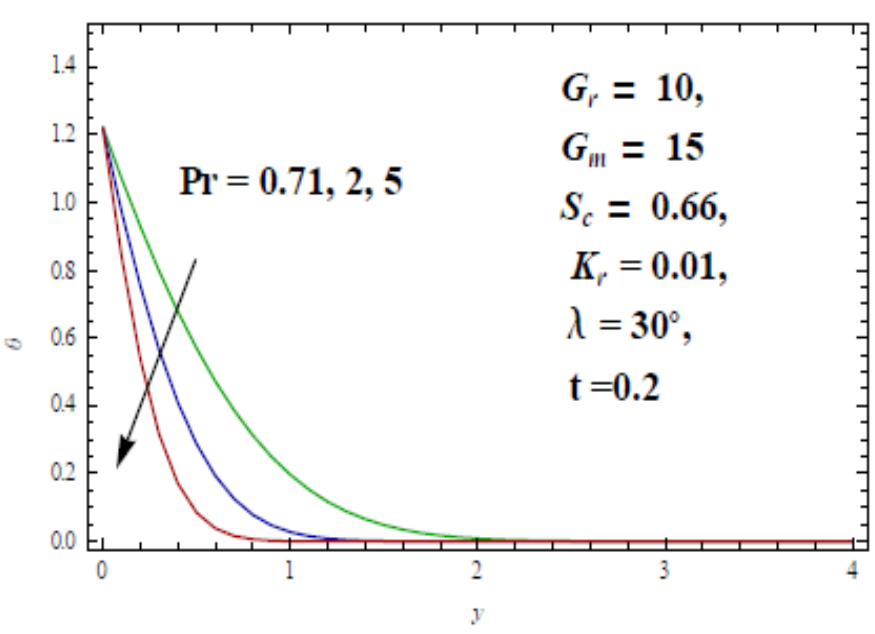

Figure 6. $\quad \begin{array}{lll}\boldsymbol{\theta} & \text { v/s } & \mathbf{P}_{\mathbf{r}}\end{array}$

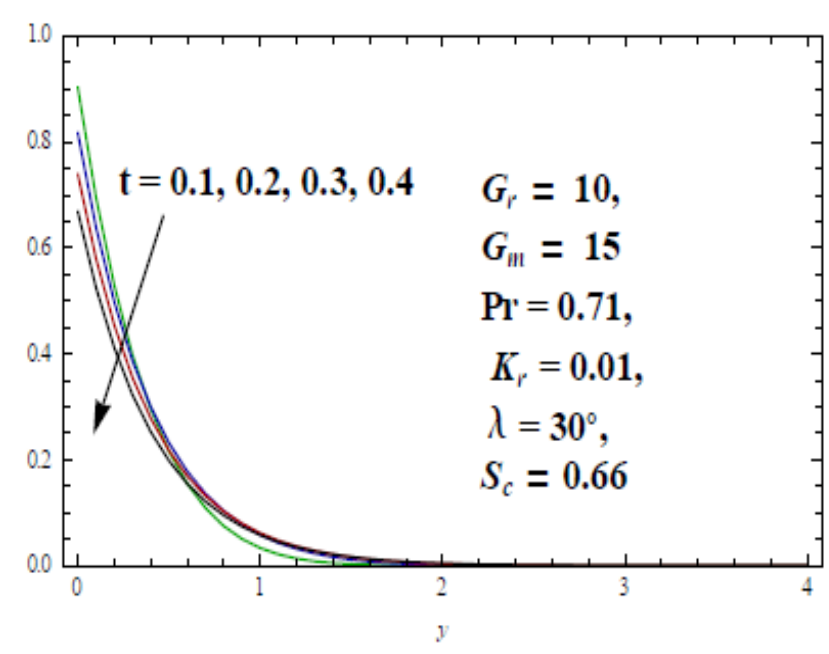

Figure 7. $\quad \mathbf{C} \quad \mathbf{v} / \mathbf{s} \quad \mathbf{t}$
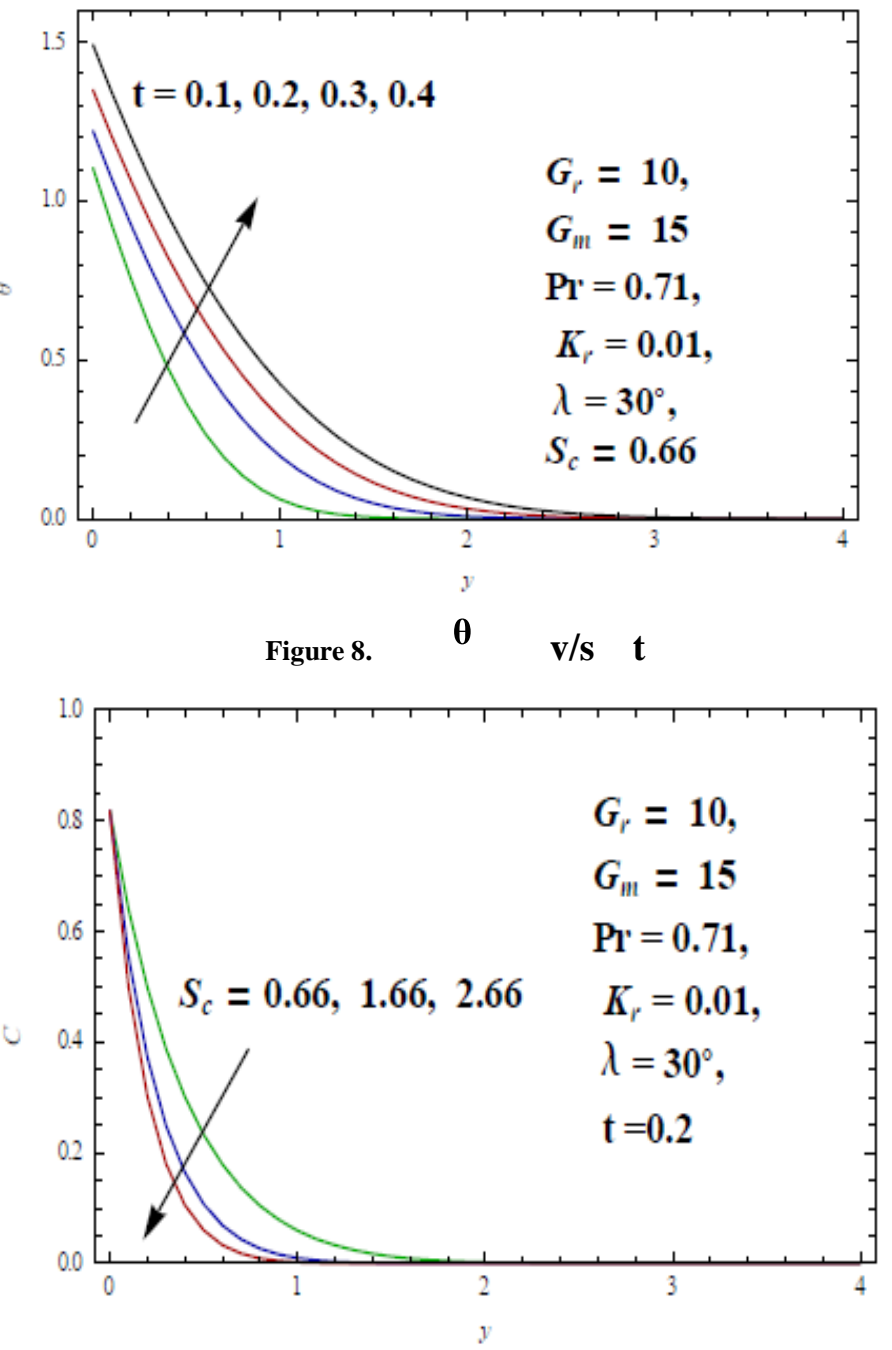

Figure 9. $\quad \mathbf{C} \quad$ v/s $\quad \mathbf{S}_{\mathbf{c}}$

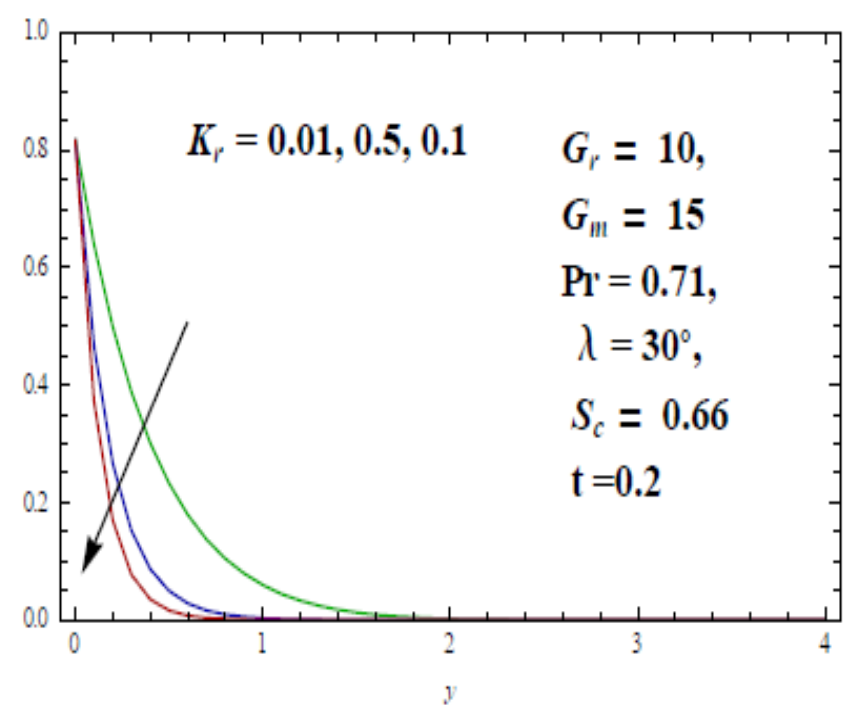

Figure 10. $\mathbf{C} \quad$ v/s $\quad \mathbf{K}_{\mathbf{r}}$ 
Table1. Skin Friction $\tau$, Nusselt number Nu and Sherwood number Sh

\begin{tabular}{|c|c|c|c|c|c|c|c|c|c|}
\hline $\mathbf{G}_{\mathbf{r}}$ & $\mathbf{G}_{\mathbf{m}}$ & $\mathbf{K}_{\mathbf{r}}$ & $\mathbf{S}_{\mathbf{c}}$ & $\mathbf{t}$ & $\mathbf{P}_{\mathbf{r}}$ & $\lambda$ & $\tau$ & $\mathbf{N u}$ & Sh \\
\hline 10 & 15 & 0.01 & 0.66 & 0.2 & 0.71 & $30^{\circ}$ & 3.55545 & 1.50801 & 1.79066 \\
\hline 10 & 15 & 0.01 & 0.66 & 0.2 & 0.71 & $45^{0}$ & 2.59301 & 1.50801 & 1.79066 \\
\hline 10 & 15 & 0.01 & 0.66 & 0.2 & 0.71 & $60^{\circ}$ & 1.33872 & 1.50801 & 1.79066 \\
\hline 10 & 15 & 0.01 & 0.66 & 0.2 & 2 & $30^{0}$ & 2.77896 & 2.47849 & 1.79066 \\
\hline 10 & 15 & 0.01 & 0.66 & 0.2 & 5 & $30^{0}$ & 2.10813 & 3.79446 & 1.79066 \\
\hline 10 & 15 & 0.01 & 0.66 & 0.1 & 0.71 & $30^{0}$ & 1.82811 & 1.78797 & 2.09119 \\
\hline 10 & 15 & 0.01 & 0.66 & 0.2 & 0.71 & $30^{0}$ & 3.55545 & 1.50801 & 1.79066 \\
\hline 10 & 15 & 0.01 & 0.66 & 0.3 & 0.71 & $30^{0}$ & 4.42197 & 1.46009 & 1.60422 \\
\hline 10 & 15 & 0.01 & 0.66 & 0.4 & 0.71 & $30^{\circ}$ & 5.0161 & 1.49073 & 1.44809 \\
\hline 10 & 15 & 0.01 & 1.66 & 0.2 & 0.71 & $30^{0}$ & 2.88859 & 1.50801 & 2.64876 \\
\hline 10 & 15 & 0.01 & 2.66 & 0.2 & 0.71 & $30^{0}$ & 2.57647 & 1.50801 & 3.19079 \\
\hline 10 & 15 & 0.05 & 0.66 & 0.2 & 0.71 & $30^{0}$ & 2.51658 & 1.50801 & 3.51665 \\
\hline 10 & 15 & 0.1 & 0.66 & 0.2 & 0.71 & $30^{0}$ & 2.12221 & 1.50801 & 4.46336 \\
\hline
\end{tabular}

\section{CONCLUSIONS}

In this work we have concluded that combined effects of variable permeability and variable magnetic field in the presence of chemical reaction on unsteady MHD flow of a viscous incompressible fluid past an inclined plate through porous medium with exponential temperature and concentration concluded the following conclusions:

1. On Increasing inclination angle and Prandlt number, Primary velocity ' $u$ ' decreases rapidly.

2. Velocity first increases with time then after some time it decreases which is physically consistent.

3. Temperature increases with time and decreases Prandlt number.

4. Concentration decreases with increase in time (t) according to the boundary condition.

5. Concentration decreases with increase in Schmidt number and chemical reaction parameter.

\section{ACKNOWLEGMENT}

We are thankful to reviewers and Editors of the journal, and software company (Mathematica) for developing the techniques that help in the computation and editing. There is no financial support for my research from any organization from anywhere.

\section{REFERENCES}

[1] E. M. Sparrow, R. D.Cess, "Effect of Magnetic field on free convection heat transfer", Int. J Heat Mass Transfer, Vol. 3, pp. 267-70, 1961.

[2] M. S. Alam, M. M. Rahman, , "Dufour and Soret effect on MHD free convective Heat and Mass transfer flow past a vertical flat plate embedded in a porous medium", Journal of Naval Architecture and Marine engineering Vol. 2, Issue 1, pp. 55-65, 2005.

[3] Z. Dursunkaya, W.M. Worek, "Diffusion thermo and thermal diffusion effects in transient and steady natural convection from vertical surface", International Journal of Heat and Mass Transfer, Vol. 35, Issue 8, pp. 2060-2065, 1992.

[4] A. Postelnicu, "Influence of a magnetic field on heat and mass transfer by natural convection from vertical surface in porous media considering Soret and Dufour effects", International Journal of Heat and Mass Transfer. Vol. 47, Issue 67, pp.14671472, 2004.

[5] A. Raptis, C. Perdikis, "Radiation and free convection flow past a moving plate", Appl. Mech. Eng., Vol. 4, Issue 4, pp. 817-821, 1999.

[6] V. Rajesh, V. K. Verma, "Radiation and mass transfer effects on MHD free convection flow past an exponentially accelerated vertical plate with variable temperature", ARPN Journal of Eng. And App. Sci., Vol. 4, Issue 6, pp.20-26, 2009.

[7] S. Shivaiah and J. A. Rao, "Chemical reaction effect on an unsteady MHD free convective flow past and infinite vertical porous plate with constant suction and heat source", Int. J. of Appl. Math. And Mech., Vol. 7, Issue 8, pp. 98-118, 2011.

[8] M.A. Alabraba, A.R. Bestman, A. Ogulu, "Laminar convection in binary mixed of Hydro magnetic flow with Radiative Heat Transfer, Astrophysics and Space Science, Vol. 195, Issue 2, pp. 431-439, 1992. 
[9] M.D. Enamul Karim, M.D. Abdus Samad, M.D. Maruf Hasan, "Dufour and Soret effect on steady MHD flow in presence of Heat generation and magnetic field past an inclined stretching sheet", Open Journal of Fluid Dynamics, Vol. 2, pp. 91-100, 2012.

[10] M.S. Quraishi and N. Pandya, "Effect of Soret and Rotation on MHD unsteady flow past an inclined infinite porous plate embedded in porous medium with heat_generation/ absorption and mass transfer", Int. J. of Mathematical Archive Vol. 8, Issue 9, pp. 74-84, 2017.

[11] N. Pandya and M. S. Quraishi, "Effect of Chemical Reaction and Rotation on MHD unsteady flow past an inclined oscillating infinite porous plate embedded in porous medium for heat generation/ absorption with mass transfer and variable temperature", Int. J. Math. And Appl., Vol. 6, Issue 1-E, pp. 965$975,2018$.

[12] T. G. Cowling, "Magnetohydrodynamic", Intersicence Publisher, New York, 1957.

[13] B. Carnahan, H. A. Luthor, J. O. Wilkes, "Applied Numerical Methods", John Wiley and Sons, New York, 1969.

\section{AUTHORS PROFILE}

Dr. Nidhi Pandya is my supervisor and Assistant Professor in the department of Mathematics and Astronomy, University of Lucknow, Lucknow, Uttar Pradesh, India. Now a day she is working on MHD viscous and viscoelastic flow in porous medium.

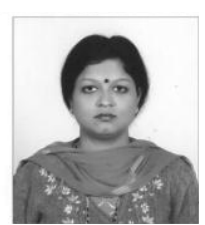

Mohammad Suleman Quraishi is a Research Scholar under the supervision of Dr. Nidhi Pandya. I am pursuing $\mathrm{Ph}$. D. degree from University of Lucknow.

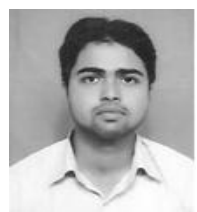

